\title{
Usage of information technology and business analytics within sales and operations planning: a systematic literature review*
}

\author{
Frédéric Niko Patrice Nicolas ${ }^{1}$, Antônio Márcio Tavares Thomé2 ${ }^{\text {, Bernd Hellingrath }}{ }^{1}$ \\ ${ }^{1}$ University of Münster, Münster, Germany. \\ 2Pontificial Catholic University of Rio de Janeiro, Rio de Janeiro, Brazil.
}

How to cite: Nicolas, F.N.P., Thomé, A.M.T. and Hellingrath, B. (2021), “Usage of information technology and business analytics within sales and operations planning: a systematic literature review", Brazilian Journal of Operations \& Production Management, Vol. 18, No. 03, e20211152. https://doi.org/10.14488/BJOPM.2021.023

\begin{abstract}
Goal: This paper aims to analyze to which extend the usage of information technology (IT) and business analytics (BA) have been explored in the context of sales and operations planning (S\&OP).

Design / Methodology / Approach: This study conducts a systematic literature review to synthesize the state of the art of IT and BA in S\&OP. The review follows the rigorous approach by Thomé et al. (2016). Through the literature search, 442 results were retrieved, of which 57 were selected for the analysis. The results containing analytics techniques are classified by the planning tasks of S\&OP that they address.

Results: The analysis provides an overview of the dominant themes in the field of IT, BA and S\&OP and leads to a classification of the existing research in the field of BA for S\&OP. This study finds that IT can be an enabler of S\&OP and that most analytics techniques address S\&OP through fullyintegrated optimization approaches. Yet, the impact on the S\&OP process has not been explored. This study thus identifies gaps for future research and proposes a research agenda on BA on S\&OP.

Limitations of the investigation: The systematic literature review is restricted to the Elvesier SCOPUS database. SCOPUS has excellent coverage regarding relevant journals for this study. Despite SCOPUS being a prominent scientific database, other databases might reveal additional studies and further insights.
\end{abstract}

Practical implications: The findings of this study provide insights on how IT and BA can support and influence the S\&OP process.

Originality / Value: In recent years, S\&OP, IT and BA have seen a growing interest by scholars. To the best of the authors' knowledge, the number of published literature reviews on S\&OP and BA is scarce. This study provides an overview of how IT and BA are used within S\&OP.

Keywords: Systematic Review; Sales and Operations Planning; Business Analytics; Supply Chain Analytics; Information Technology.

\footnotetext{
*This article is from the XXVI International Conference on Industrial Engineering and Operations Management (IJCIEOM) and was invited to be published in the September/2021 Special Issue of the Brazilian Journal of Operations \& Production Management, due to its relevance and contribution to the field.
}

Financial support: None.

Conflict of interest: The authors have no conflict of interest to declare.

Corresponding author: frederic.nicolas@wi.uni-muenster.de

Received: 23 Jan 2021.

Approved: 26 Jan 2021

Editor: João Reis 


\section{INTRODUCTION}

The rapid rise of information technology (IT) has been notably driven by the need to process the ever-growing amount of data faster and in a reliable way, as it is widely argued that the availability of more information results in more data-oriented and informed decision making (Dutta and Bose, 2015; Klein et al., 2018; Schoenherr and Speier-Pero, 2015; Singh et al., 2017). Therefore, it is not a coincidence that big data has evolved to become an asset for organizations (Nguyen et al., 2018). The necessary analytical methods and techniques to gain meaningful insights from the large collections of data sets generated by the organizations have been defined as big data analytics (BDA) (Jeble et al., 2018; Kamble and Gunasekaran, 2020). BDA thereby is a subset of the broader term "business analytics (BA), which includes the people, processes, and technologies that turn data" into business insights (Wixom et al., 2013, p. 111). Information system capabilities support the organizations in the process of collecting, processing, and assimilating information, as well as in formulating an efficient response (Cadez and Guilding, 2008; Dale Stoel and Muhanna, 2009; Trkman et al., 2010). Organizations employ the generated information in various functions, ranging from purchasing and operations, over marketing and sales, up to after-sales services (Hopkins and Brokaw, 2011; Sanders, 2014; Yu et al., 2018). To leverage the information across the various functions, recent literature calls for a collaborative interdisciplinary approach that involves "experts from different domains who would help on the maximum utilization of this resource" (Kamble and Gunasekaran, 2020, p.15).

A prevalent interdisciplinary process on the tactical planning level is sales and operations planning (S\&OP), whose two main purposes are to balance supply and demand and to build bridges between strategic and operational plans of the organization (Thomé et al., 2012). It thereby provides a platform for horizontal and vertical integration of information that can lever the tactical decision-making process. When applied successfully, S\&OP can improve the organization's business performance (Seeling et al. 2019). The application of analytics is not a new phenomenon and operations management has been around for several years in the context of supply chains (Souza, 2014) and with it also analytical approaches towards S\&OP (e.g. Feng et al., 2010; Lim et al., 2017; Ben Ali et al. 2019). Despite being a prevalent planning process in the industry, an initial literature search on Elvesier's Scopus database for the terms ("big data analytics" OR "BDA") AND ("sales and operations planning" OR "S\&OP") revealed no results. Thus, hinting a gap in the literature and calling for in-depth research on the application of BDA in S\&OP. As BDA has recently emerged as a growing research area with promising significant influences on several elements of S\&OP, the authors of this study suggest extending the research to the broader area of BA (Mishra et al., 2016).

This review aims to investigate the use of technology and BA in S\&OP and their influence on the S\&OP process. Thereby this study includes the factors technology and process of BA, which are also dimensions frequently described in frameworks and maturity models for S\&OP (e.g., Danese et al., 2018; Grimson and Pyke, 2007; Hulthén et al., 2016; Kristensen and Jonsson, 2018; Lapide, 2005; Noroozi and Wikner, 2016; Thomé et al., 2012; Tuomikangas and Kaipia, 2014). The impact of people on BA and S\&OP is not in the scope of this study. Thus the research is subdivided into two parts. First, the utilization of IT and its role in S\&OP is investigated, as it is the existing technological basis on which BA can build. Secondly, the application of BA for the individual tasks of S\&OP is explored. It aims at investigating the effect of BA on organizational processes within S\&OP. This study thus answers the following research questions:

$R Q 1$ : Which aspects of IT have been explored in the context of S\&OP?

RQ2: Which tasks of $S \& O P$ have been addressed by business analytics?

$R Q 3:$ What are future research areas for $\mathrm{BA}$ and $\mathrm{S} \& \mathrm{OP}$ ?

The main goal of this paper is threefold: (i) to summarize the state of the art in the research of IT in S\&OP, (ii) to provide an overview of the utilization of BA for S\&OP by classifying them by the individual tasks addressed, and (iii) to provide an agenda for future research in 
the areas of BA and S\&OP. Thereby, this study aims to contribute to the further evolution of $S \& O P$ towards a data-driven process.

This paper is organized into three parts. First, the methodology for the systematic literature review is described. Next, the search results are analyzed and discussed regarding the research questions. Finally, the conclusion and outlook on future research close the paper.

\section{METHODOLOGY}

For a reliable and replicable analysis with a transparent and scientific approach, the methodological approach is a systematic literature review (Thomé et al., 2016; Tuomikangas and Kaipia, 2014). The systematic literature review follows the eight-step process described by Thomé et al. (2016): (i) Planning and formulating the problem, (ii) searching the literature, (iii) data gathering, (iv) quality evaluation, (v) data analysis and synthesis, (vi) interpretation, (vii) presenting results, (viii) updating the review.

In the first step, the research questions, as well as their expected results, were defined. In the following, the literature search and data gathering steps are combined and carried out in line with the procedure outlined in Thomé et al. (2012), which covers the steps in more detail. The procedure includes the following five steps: (i) Computerized database selection, (ii) identification of keywords for search, (iii) criteria for the exclusion of studies, (iv) manual review of selected abstracts by two authors, and (v) full-text review of selected papers. Elvesier's Scopus was selected as the database of choice. Using a single database increases the degree of transparency and facilitates replicability. Furthermore, Scopus indexes a large number of journals within the article's topic (IT and BA), when compared with other international databases (Mongeon and Paul-Hus, 2016). Table 1 shows the selected keywords, which cover a broad scope in the areas of BA and IT. For the latter, the generic terms "information system" ${ }^{\star \prime}$ and "information technolog*" were part of the search string, as well as some common types of systems that can support BA. Besides the terms BA and BDA, this study also includes the keyword "analytic*" to capture related terms and is extended to include supply chain analytics (SCA). Thereby SCA refers to BA used in a supply-chain context (Chae and Olson, 2013). Furthermore, the keyword "maturity" comprises existing maturity models, as they often describe dimensions related to organizational structure and IT in S\&OP. Each of the keywords was searched in combination with the terms "Sales and Operations Planning" OR "S\&OP". Following Thomé et al. (2012), "S OP" was not included in the search term to avoid results from the field of chemistry. The search covered the search fields title, abstract, and keywords.

Table 1. Keywords of literature search

\begin{tabular}{ccc}
\hline Search Keywords & Keyword's abbreviation & No. of results \\
\hline Information System* & IS & 210 \\
Information Technolog* & IT & 97 \\
\hline Data & - & 57 \\
\hline Enterprise Resource Planning & ERP & 19 \\
\hline Maturity & - & 16 \\
\hline Advanced Planning System* & APS & 11 \\
\hline Analytic* & - & 10 \\
\hline Decision Support System* & DSS & 10 \\
\hline Business Intelligence & BI & 7 \\
\hline Machine Learning & ML & 2 \\
\hline Supply Chain Analytic* & SCA & 2 \\
Business Analytic* & BA & 1 \\
\hline Big Data Analytic* & BDA & 0 \\
\hline
\end{tabular}

Source: The authors themselves 
The results of the literature search are illustrated in Figure 1. The individual searches resulted in 442 results before and 227 after removing duplicates. An initial independent review of the abstracts resulted in a Krippendorff's Alpha of $\alpha=0.71$ (Krippendorff, 1970). After aligning the exclusion criteria among the authors, the agreement rate was $\alpha=0.982$, which is well-above the threshold of $\alpha=0.8$ deemed acceptable (Krippendorff, 2004). This resulted in 99 papers in English eligible for full-text assessment. Further, 42 papers were eliminated during the assessment due to missing relevance, low academic value, or missing access. Figure 2 illustrates the number of publications per year for the 57 papers included in this study. It shows continued interest and overall growth of publications in the investigated field. The quality of the assessed papers was evaluated by type and origin. Figure 3 illustrates the share of publication by document type. With $67 \%$, the majority of the publications were articles published in journals, followed by $23 \%$ in conference proceedings. Reviews (9\%) and book chapters (2\%) make up a minority of the search results.

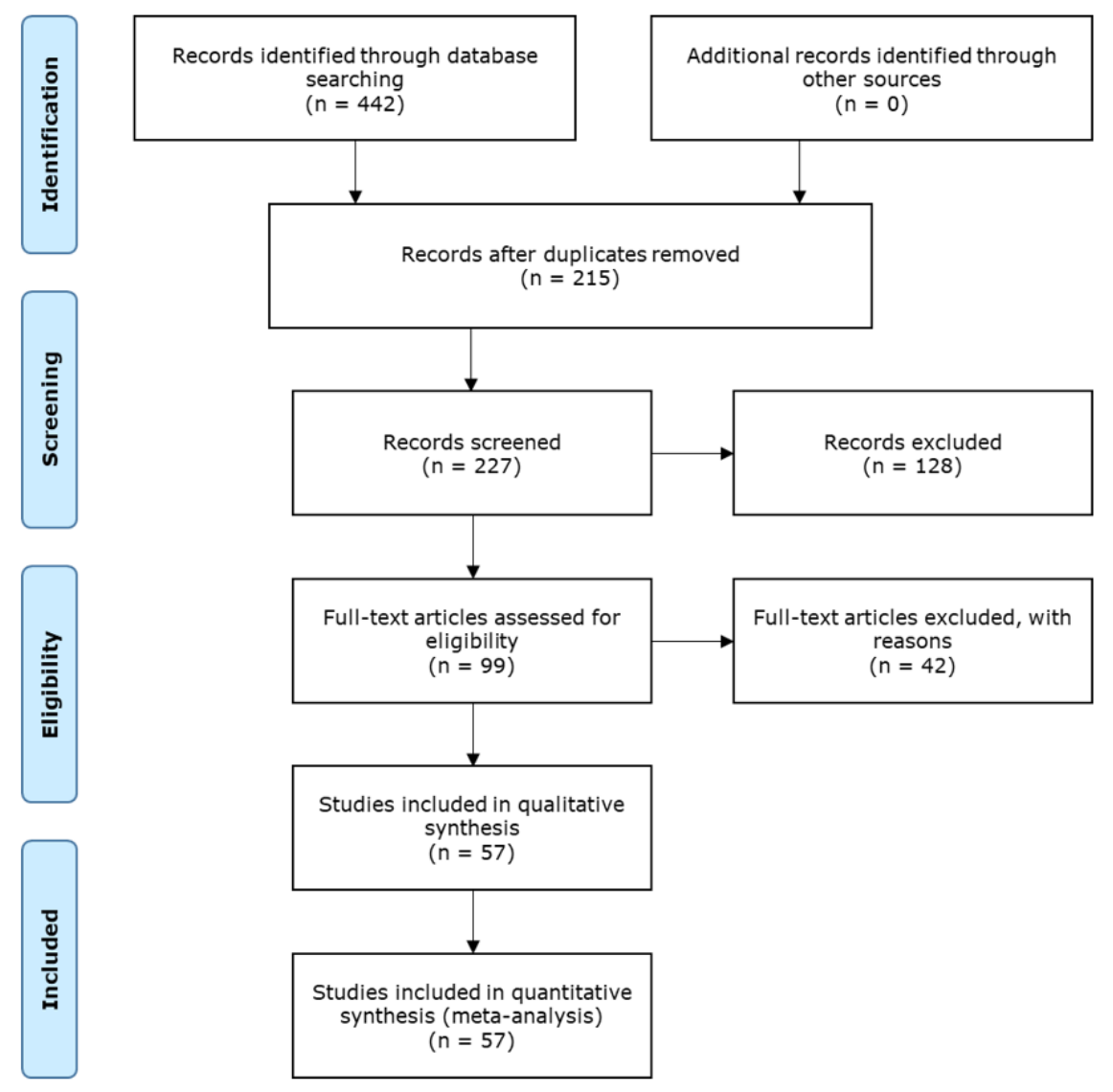

Figure 1. PRISMA flow diagram for inclusion and exclusion of studies

Source: Moher et al. (2009)

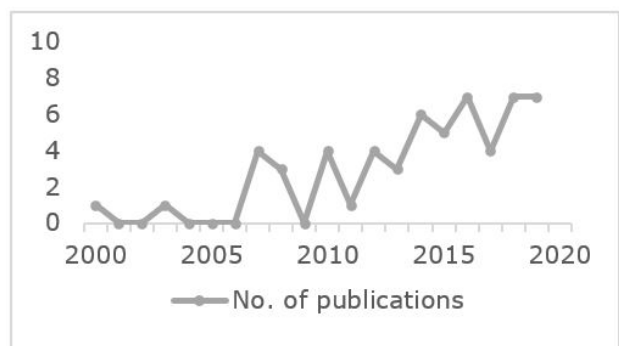

Figure 2. Search results by year

Source: The authors themselves 


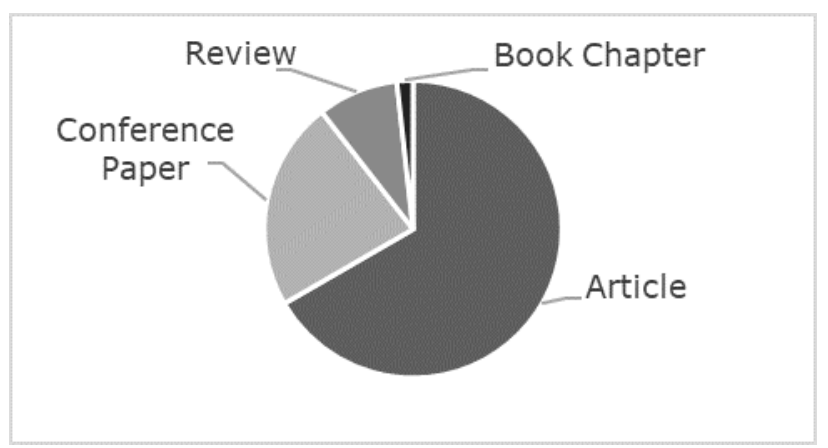

Figure 3. Search results by document type Source: The authors themselves

For the analysis, each selected paper has been read several times in full and the content was analyzed in a matrix, with columns for the respective research questions. The results were then synthesized and interpreted in this study. As suggested by Thomé et al. (2016) a future research agenda is finally derived logically from the critical review.

The following section represents the data analysis and synthesis, as well as the interpretation. It includes a qualitative analysis for RQ1 and a classification of the results for RQ2. The paper itself represents the seventh step of the systematic literature approach. The eighth and final step is updating the review, which is beyond the scope of this study.

\section{ANALYSIS AND DISCUSSION}

Trkman et al. (2010) find "that companies [that] support their analytical capabilities with good IS are likely to be more capable of performing better" (p. 324). As mentioned before, the literature has explored the IT dimension to some extent. The literature search also reflects these findings as roughly half of the papers retrieved investigate IT related themes. Therefore, first, the aspects of IT that influence S\&OP are analyzed to answer the first research question. Secondly, an in-depth analysis of the usage of BA in the context of the tasks of S\&OP answers the second research question. Lastly, we propose a future research agenda.

\section{Information Technology}

Various authors have developed maturity models as guidelines for the implementation of S\&OP. One of the most widespread studies is Grimson and Pyke (2007), which summarizes S\&OP maturity models (Thomé et al., 2012). Their resulting maturity model includes an IT dimension that ranges over five different maturity stages from Excel spreadsheets over MRP integration and dedicated optimization software until real-time integrated solutions for joint optimization. Wagner et al. (2014) and Shaikh (2018) define a similar dimension in their maturity model. Danese et al. (2018) build their research on the model of Grimson and Pyke (2007) and further investigate the required steps for a company to evolve through the maturity stages. Vereecke et al. (2018) develop a maturity assessment model for demand planning, with dimensions for data management, forecasting methods, and forecasting systems.

Although many maturity models include IT as a dimension for S\&OP, Kristensen and Jonsson (2018) point out that there are "contradictory findings regarding the role of IT systems for supporting S\&OP" (p.34). Pedroso et al. (2016) find that information systems can, on the one hand, act as an enabler for the implementation of S\&OP, but also that, on the other hand, inadequate technology and information systems can become a barrier for the process. Goh and Eldridge (2019) find that information acquisition and processing in the context of S\&OP has a positive effect on supply chain performance. Song et al. (2008), on the other hand, find that the impact of information acquiring and mining, information integration and sharing, and information automating and monitoring on firm performance is not solely dependent on the IT applications but rather on how the organization implements these functions. Suurmond (2016) strengthens this with his findings that software by itself does not solve the challenges when implementing various information into S\&OP. This study follows the predominant 
tendency that IT is an enabler of S\&OP when it is aligned with the other dimensions of S\&OP and embedded in the organizational processes.

The conflicting view on IT in S\&OP has also been noticed by other authors such as Thomé et al. (2012), who ultimately include information systems, with their sub-dimensions "systems and software" and "models and simulation", as a process descriptor into their framework. Also, Tuomikangas and Kaipia (2014) refer to "S\&OP tools and data" as a coordination mechanism, which encompasses various constructs for the collection, processing, and storing of information, as well as the proper output of information to support S\&OP. To address the gap in selecting adequate technology in the context of a firm's S\&OP process, Garcia-Villarreal et al. (2018) propose a supporting selection framework.

The literature also takes a closer look at various information systems. Mathrani (2018) finds that enterprise systems support the maximization of value for service processes in S\&OP. Plank and Hooker (2014) show that interactive marketing tools can benefit the S\&OP process and the entire supply chain. Olhager and Selldin (2007a, 2007b) find that the end product characteristics and environmental factors dictate the design choice of manufacturing planning and control systems for S\&OP and that S\&OP has a significant positive impact on operational performance. Furthermore, various authors have investigated the use of advanced planning and scheduling (APS) systems in S\&OP. As such, Doering and Suresh (2016) identify the use of advanced systems as a valid construct of forecasting management competencies, with a higher impact in repetitive environments. Ivert and Jonsson (2010) identify 18 potential benefits spreading over the three categories decision support, planning efficiency, and learning effects for the use of APS systems in S\&OP. In a further study, Ivert and Jonsson (2014) identify individual, technological, and organizational dimensions that affect the use of APS systems in S\&OP.

Even though the literature addresses various systems, Jonsson and Holmström (2016) point out that the adoption of optimization and scenario planning is increasing, but also that "basic computer applications [are] still not widely implemented in practice" (p. 75). Therefore, Ross (2003) argues that a modular implementation that is embedded in a holistic program helps in the introduction of supply chain optimization software. These findings further indicate that IT needs to be linked to the other dimensions of S\&OP.

Although there are diverging views on the role of IT in S\&OP, most studies found in this literature research point towards IT having a positive impact on S\&OP. Thereby the level of technological integration must be matched to the maturity of the S\&OP process to yield benefits on the firm performance. The integration of advanced systems, especially APS systems, thereby support more efficient decision-making and provide an anchor point in the organization for most of the optimization techniques discussed in the following section.

\section{Business Analytics}

In the following, the retrieved results covering analytical techniques are analyzed and classified to answer RQ2. While many of the publications analyzed in the previous section discuss the role of IT and planning systems on a conceptual level, solely Chae and Olson (2013) specifically investigate the integration of BA into supply chain management from a conceptual perspective and transfer their findings to the context of S\&OP. They connect the proposed SCA framework to S\&OP and find that companies need to invest in data management, analytical supply chain process- and supply chain performance management capabilities to take advantage of BA in supply chains. The data management capabilities refer to the firm's ability to gather, store, and process data. The analytical supply chain process capabilities (APC) refer to the application of analytical techniques in the planning processes of the focal firm. Supply chain performance management capabilities refer to the ability to observe, orient, and decide based on supply chain metrics or KPIs. In their study, Chae and Olson (2013) derive APC for the plan, source, make, and deliver processes of the SCOR framework, and apply their findings to the S\&OP process. This section also examines the analytical processes but differs from the work by Chae and Olson (2013) by classifying the analytics techniques identified in the existing literature on S\&OP into their respective tasks. This view allows for a better understanding of how BA interconnects the planning tasks in the cross-functional context of S\&OP.

The planning tasks for the classification are deducted from the typology of inputs for S\&OP by Thomé et al. (2012), which are demand, source, production, delivery, and finance. 
While their typology contains various input levels for plans, constraints, and others, this classification is limited to the planning tasks. The proposed classification, as illustrated in Table 2, adopts the following tasks: (i) the demand category with its sub-categories forecasting (FC) and demand planning (DP), which refers to the extended planning and alignment of plans, (ii) source, (iii) production planning (PP), (iv) logistics planning, which subdivides into inventory planning (IP) and transportation planning (TP), (v) finance, and (vi) fully integrated (FI) models, which are models that aim at optimizing the entire S\&OP process. The analytics techniques were classified by the association of the utilized decision variables or constraints. FI models include those models that are classified into four or more main categories.

The optimization methods subsumed in the forecasting classification of the demand category show the least integration with other planning tasks described in the classification. As such, Omar et al. (2016), Kim et al. (2019), and Caglayan et al. (2020) use machine learning in the form of neural networks to enhance forecasting. Wood et al. (2017), for their part, develop a framework for implementing sentiment analysis in conventional S\&OP processes. And Kaipia et al. (2017) discuss the mechanisms on the integration of point of sales data. A reason for the sparse integration with other tasks is that the outcomes of these studies serve as a baseline input for the following steps of the S\&OP process, and the forecasting process itself rather relies on external factors, such as data and information collection and exchange, as well as the processes related to it. This is further supported by Fildes et al. (2019), who study the use of information from forecasting support systems by demand with internal tasks. The methods in this category aim at aligning the demand and capacities of the other functions. Few studies, such as Feng et al. (2013), who include demand contracts into a supply chain S\&OP model, and Ben Ali et al. (2018a), who employ simulation to mimic various configurations for integrated demand management processes, introduce new constraints from the demand side. Most models limit the alignment of plans to an overall cost or profit objective.

Table 2. Classification of business analytics methods in S\&OP by planning task

\begin{tabular}{|c|c|c|c|c|c|c|c|c|}
\hline \multirow{2}{*}{ Authors } & \multicolumn{2}{|c|}{ Demand } & \multirow{2}{*}{ Source } & \multirow{2}{*}{ Production } & \multicolumn{2}{|c|}{ Logistics } & \multirow{2}{*}{ Finance } & \multirow{2}{*}{$\mathbf{F I}$} \\
\hline & FC & DP & & & IP & TP & & \\
\hline $\begin{array}{l}\text { (Caglayan et al., 2020; Omar et al., } \\
\text { 2016) }\end{array}$ & $\checkmark$ & & & & & & & \\
\hline (Fildes et al., 2019) & $\checkmark$ & $\checkmark$ & & & & & & \\
\hline (Calfa et al., 2015) & & & & $\checkmark$ & & & & \\
\hline $\begin{array}{l}\text { (Genin et al., 2007; Thomas et al., } \\
\text { 2008; Thomas and Lamouri, 2000) }\end{array}$ & & & & $\checkmark$ & $\checkmark$ & & & \\
\hline (Wery et al., 2018) & & $\checkmark$ & & $\checkmark$ & & & & \\
\hline (Kim et al., 2019) & $\checkmark$ & $\checkmark$ & & & $\checkmark$ & & & \\
\hline (Ben Ali et al., 2018a) & & $\checkmark$ & & $\checkmark$ & & & $\checkmark$ & \\
\hline (Sodhi and Tang, 2011) & & $\checkmark$ & & & $\checkmark$ & & $\checkmark$ & \\
\hline $\begin{array}{l}\text { (Anand Jayakumar et al., 2016; } \\
\text { Lim et al., 2014; Lim et al., 2017, } \\
\text { 2015, 2013) }\end{array}$ & & $\checkmark$ & $\checkmark$ & & $\checkmark$ & & & \\
\hline (Rappold and Yoho, 2014) & & $\checkmark$ & & $\checkmark$ & $\checkmark$ & & & \\
\hline (Chen-Ritzo et al., 2010) & & & $\checkmark$ & $\checkmark$ & $\checkmark$ & & & \\
\hline (Wochner et al., 2016) & & $\checkmark$ & & $\checkmark$ & $\checkmark$ & $\checkmark$ & & $\checkmark$ \\
\hline (Hahn and Kuhn, 2012a, 2012b) & & $\checkmark$ & & $\checkmark$ & $\checkmark$ & & $\checkmark$ & $\checkmark$ \\
\hline (Taşkin et al., 2015) & $\checkmark$ & $\checkmark$ & $\checkmark$ & $\checkmark$ & $\checkmark$ & & & $\checkmark$ \\
\hline $\begin{array}{l}\text { (Feng et al., 2010, 2008; } \\
\text { Nemati et al., 2017; Nemati and } \\
\text { Alavidoost, 2019; Wang et al., 2012) }\end{array}$ & & $\checkmark$ & $\checkmark$ & $\checkmark$ & $\checkmark$ & $\checkmark$ & & $\checkmark$ \\
\hline (Ben Ali et al., 2018b) & & $\checkmark$ & & $\checkmark$ & $\checkmark$ & $\checkmark$ & $\checkmark$ & $\checkmark$ \\
\hline $\begin{array}{l}\text { (Ben Ali et al., 2019; Feng et al., } \\
\text { 2013; Wang and Hsu, 2010) }\end{array}$ & & $\checkmark$ & $\checkmark$ & $\checkmark$ & $\checkmark$ & $\checkmark$ & $\checkmark$ & $\checkmark$ \\
\hline
\end{tabular}




\begin{tabular}{|c|c|c|c|c|c|c|c|c|}
\hline \multirow{2}{*}{ Authors } & \multicolumn{2}{|c|}{ Demand } & \multirow{2}{*}{ Source } & \multirow{2}{*}{ Production } & \multicolumn{2}{|c|}{ Logistics } & \multirow{2}{*}{ Finance } & \multirow{2}{*}{ FI } \\
\hline & FC & DP & & & IP & TP & & \\
\hline Total & 5 & 26 & 15 & 21 & 25 & 11 & 8 & 13 \\
\hline
\end{tabular}

Source: The authors themselves

Sourcing is mainly considered in the $\mathrm{Fl}$ models and in the optimization models from Lim et al. $(2017,2015,2014,2013)$. They focus on procurement in the automotive industry and develop optimization models for distant suppliers with flexibility rates. Its consideration is mostly limited to internal decision factors such as supplier selection and capacity or lead-time constraints. The integration of information and optimization across supply chain members is not studied.

A predominant topic in the production planning classification of the demand planning category is the variability of production. Here Calfa et al. (2015) examine production planning under demand volatility. Thomas and Lamouri (2000), Genin et al. (2007), and Thomas et al. (2008) develop models for robust and stable supply plans. Furthermore, Wochner et al. (2016) realize a model to optimize production for ramp-ups and new product introduction. The optimization models of the production planning tasks are closely interconnected with the demand planning tasks.

In logistics planning, the inventory planning tasks have a significant overlap with the optimization methods classified in production planning and demand planning, as the aligned production and demand plans induce the inventory plan. While Rappold and Yoho (2014) explicitly consider optimization methods for inventory management, most optimization models restrict inventory planning to capacity constraints. Analogous to the source category, the transportation planning tasks are predominantly addressed in the $\mathrm{Fl}$ models. The constraints focus on the factors related to transportation cost and capacity. Advanced analytics techniques that consider external factors, such as traffic- or weather information, are not applied in the context of S\&OP.

The integration of financial planning into $S \& O P$ is still a very scare research field, as has already been pointed out by Thomé et al. (2012). Wang and Hsu (2010) propose an integrated model that takes financial flows, such as lead-time of payment, into account. Anand Jayakumar et al. (2016) build a model for revenue maximization, which includes marketing decisions for the scheduling of promotional activities. Furthermore, Ben Ali et al. (2018b, 2019) include revenue management in a production system. Hahn and Kuhn (2012a) use robust optimization methods to integrate valuebased performance and risk optimization into an integrated S\&OP model. They further extend that model by "taking into account related (dis-)investment and financial decisions" (Hahn and Kuhn, 2012a, p. 560).

In the context of the collaborative cross-functional nature of the S\&OP process, it is not surprising to see that all but three of the results identified in this study are classified in more than one category. Thereby the degree of integration and the combination of tasks vary. Some optimization models explicitly aim to solve plans for various functions, while others create implicit dependencies by connecting constraints. 13 papers, which aim to integrate optimization across the majority of the involved functions, were classified as Fl. Thereby various studies have shown the benefits of these integrated planning. As such, Feng et al. (2008, 2010), Nemati et al. (2017), and Nemati and Alavidoost (2019) all find that fully integrated S\&OP planning models outperform partially integrated and decoupled planning models. Although the analytics methods across the literature show a high degree of integration across functions, it remains unclear how organizations can embed these models within the S\&OP process. The linkages between the functions in the form of decision variables or constraints require a high degree of integration and collaboration that has to be backed by organizational processes. The retrieved papers did not elaborate on the integration into the S\&OP process. Thus, especially FI models are in conflict with the traditional S\&OP process that Wallace and Stahl (2008) describe as a sequential five-step process (Thomé et al., 2012). When implementing such interconnected models, the organizational processes need to support the 
agility required to adapt to address the events derived from the results, rather than following a fixed path.

The majority of the analytic techniques retrieved in this literature search are mathematical programming optimizations, such as linear or stochastic programming, or simulations. Few solutions employ other analytics techniques, or like Taşkin et al. (2015) integrate the optimization into a decision support system. These findings further underline the initial discovery that BDA has not yet been applied to S\&OP. Furthermore, the examined papers neither show an up- or downstream integration of supply chain partners into the planning process nor an integration of external data. It shows that the application of analytics is currently limited to the internal supply chain.

The retrieved studies mainly focus on demand planning (26), production planning (21), and inventory planning (25). Sourcing (15) and transportation planning (11) related tasks are moderately represented, though their consideration is mostly limited to cost or capacity constraints. Forecasting (5) and financial planning (8) account for the fewest results. The lack of forecasting methods in this literature search indicates that the literature on forecasting techniques does not necessarily point back to the integration into S\&OP. It further reveals that - besides the techniques themselves - the factors which enable a successful forecast for S\&OP have not been examined yet. This gap also extends to the other tasks examined in this classification. Although more papers aim at optimizing these tasks, the factors that enable the implementation of analytic techniques and the impact on the planning and decision-making processes are not researched.

\section{Future Research Agenda}

Based on the results of the analysis, this section offers future research directions. It thereby answers the third research question. The authors of this study believe that the research on these topics can be expected to contribute to the further development of S\&OP. The four proposed topics for the research agenda are depicted in Table 3.

Table 3. Future research topics

\begin{tabular}{cc}
\hline Research Stream & Research Topic \\
\hline Business analytics & Applications of big data and BA in S\&OP \\
Theory building & Capability perspective of S\&OP \\
\hline Business analytics & Implementation of BA in the S\&OP process design \\
\hline Supply chain integration & Integration of external data into S\&OP \\
\hline
\end{tabular}

Source: The authors themselves

\section{Applications of big data and BA in S\&OP}

This study has found that BA techniques have been developed for numerous planning tasks of S\&OP. Yet, the extent to which BA can enhance planning and decision-making remains unknown. Furthermore, as mentioned in the introduction, big data and BDA applications have yet to be studied in the context of S\&OP. This study could not find any applications either. On the other hand, there are calls from the field of BDA for collaborative planning approaches (Kamble and Gunasekaran, 2020). Future research should thus analyze to what extent the application of big data and BA enhances planning and decision-making in S\&OP.

\section{Capabilities perspective of S\&OP}

This study has found that the role of IT has been widely explored. It showed that the successful integration of IT is dependent on the maturity of the S\&OP process. The appropriate level of IT integration is thereby an enabler for the process and data-driven decision making and results in a positive impact on firm performance. To further elaborate on the role of IT and other enablers of S\&OP, the authors suggest a comprehensive investigation on how the enablers of S\&OP can be consolidated with a founded theory. The resource-based theory of 
the firm, which has been suggested by previous authors (Ivert et al., 2015; Kristensen and Jonsson, 2018), and the theory of dynamic capabilities could be used to delineate the enablers as resources and capabilities.

\section{Implementation of BA in the S\&OP process design}

Several studies identified in this review point towards fully integrated optimization models outperforming decoupled planning models (Feng et al., 2010; Feng et al., 2008; Nemati and Alavidoost, 2019). However, none elaborate on how such models can be implemented into the S\&OP process. The alignment of plans through optimization models constitutes a substantial change to the dynamics of the S\&OP process. This integrated planning approach thus contrasts the often depicted sequential view on the tasks of the S\&OP process, thereby raising the question of whether the implementation of integrated BA techniques requires an altogether different design of S\&OP. It should thus be investigated whether the implementation of BA changes the design of the S\&OP process.

\section{Integration of external data into S\&OP}

The analytics techniques found in this research relied on intra-organizational data sets. Advanced maturity levels of S\&OP recommend the integration of supplier and customer data into the planning (Grimson and Pyke, 2007). However, external factors and the integration of thirdparty planning tasks or data into the forecasting, transportation, and sourcing tasks have not been studied. Future studies could thus draw insights from the field of supply chain integration to research how IT and BA in S\&OP can facilitate the planning process across the supply chain.

\section{CONCLUSION}

The systematic literature review was conducted in January 2020, and it includes the results for the articles indexed in the database of choice at that time. At the point of its conception, it is, to the best of the authors' knowledge, the first study of its kind to provide an overview of how both technology and analytics are used in S\&OP. The systematic literature review protocol that was followed through the study allows for robust and reproducible results. Although controversially discussed in the literature, this study shows that technology plays a vital role in S\&OP and that BA can be employed in the various planning tasks.

The role of IT in S\&OP has been explored on various levels. Foremost, maturity models have included IT as a key dimension of S\&OP and describe the use of information systems on a high level. Other studies have explored the various information systems on a more detailed level. It can be concluded that the level of IT integration can be an enabler for S\&OP when it matches the maturity of the S\&OP process. This study further identified that analytics techniques have been developed for all major planning tasks of S\&OP, from sourcing, over production-, logistics-, and demand planning, up to financial planning. Thereby it showed that the majority of the identified search results approach the planning process from a crossfunctional and integrated approach. The analysis further showed that most of the analytics techniques used are mathematical optimizations. The integration of other BA technologies into S\&OP is scarce, and the use of BDA for S\&OP has not yet been explored. Together with the aforementioned implementation of integrated BA techniques, changes to the S\&OP design seem worthwhile to be explored in future research.

Based on the findings of the systematic literature review, this study proposes a future research agenda that consists of the four topics: (i) applications of big data and BA in S\&OP, (ii) capabilities perspective of S\&OP, (iii) implementation of BA in the S\&OP process design, and (iv) integration of external data into S\&OP. The consequent exploration of these research topics is needed to explore and explain how data-driven planning and decision-making can support and transform S\&OP and how this can help firms to yield a competitive advantage. Future researchers may thus further contribute to the research on how the design and execution of S\&OP as a business process can be generalized. 
This study offers multiple opportunities for practitioners that strive to support their S\&OP process through IT and BA. Managers and consultants can use the results (1) to assess the role of IT in the firm's S\&OP process, (2) to identify planning tasks for which supporting BA techniques have been developed and to identify how those techniques promote integrated planning, and (3) to support decisions on whether to invest and improve current IT and BA capabilities and infrastructure or to reconsider the conceptualization of their S\&OP process, as well as to further develop their strategy on how to expand data-driven decision-making in the future.

This study has been limited to the results of the SCOPUS database. Further research should investigate the use of BA for the individual planning task on a tactical level, which might not themselves point back towards S\&OP, in order to explore the topic to its full extent. Furthermore, one should consult additional sources, such as the databases Web of Science, Proquest, or Ebscohost.

\section{REFERENCES}

Anand Jayakumar, A., Krishnaraj, C. and Kasthuri Raj, S.R. (2016), "LINGO based revenue maximization using aggregate planning", Journal of Engineering and Applied Sciences, Vol. 11, No. 9, pp. 6075-81.

Ben Ali, M., D'Amours, S., Gaudreault, J. et al. (2019), "Integrating revenue management and sales and operations planning in a Make-To-Stock environment: softwood lumber case study", INFOR: Information Systems and Operational Research, Taylor \& Francis, Vol. 57, No. 2, pp. 314-41. http://dx.doi.org/10.1080/03155986.2018.1554420.

Ben Ali, M., D'Amours, S., Gaudreault, J. et al. (2018a), "Configuration and evaluation of an integrated demand management process using a space-filling design and Kriging metamodeling", Operations Research Perspectives, Elsevier Ltd, Vol. 5, pp. 45-58. http://dx.doi.org/10.1016/j.orp.2018.01.002.

Ben Ali, M., D'Amours, S., Gaudreault, J. et al. (2018b), “Simulating an integrated revenue management approach in a production system with product substitution", 2018 Winter Simulation Conference (WSC), Vol. 10, IEEE, pp. 3217-3228.

Cadez, S. and Guilding, C. (2008), "An exploratory investigation of an integrated contingency model of strategic management accounting", Accounting, Organizations and Society, Elsevier Ltd, Vol. 33, No. 78, pp. 836-63. http://dx.doi.org/10.1016/j.aos.2008.01.003.

Caglayan, N., Satoglu, S.I. and Kapukaya, E.N. (2020), "Sales forecasting by artificial neural networks for the apparel retail chain stores", in Intelligent and fuzzy techniques in big data analytics and decision making, Springer International Publishing, Cham, pp. 451-56.

Calfa, B.A., Agarwal, A., Bury, S.J. et al. (2015), "Data-driven simulation and optimization approaches to incorporate production variability in sales and operations planning", Industrial \& Engineering Chemistry Research, Vol. 54, No. 29, pp. 7261-72. http://dx.doi.org/10.1021/acs.iecr.5b01273.

Chae, B.K. and Olson, D.L. (2013), "Business analytics for supply chain: A dynamic-capabilities framework", International Journal of Information Technology \& Decision Making, Vol. 12, No. 1, pp. 9-26. http://dx.doi.org/10.1142/S0219622013500016.

Chen-Ritzo, C.H., Ervolina, T., Harrison, T.P. et al. (2010), "'Sales and operations planning in systems with order configuration uncertainty", European Journal of Operational Research, Vol. 205, No. 3, pp. $604-$ 14. http://dx.doi.org/10.1016/j.ejor.2010.01.029.

Dale Stoel, M. and Muhanna, W.A. (2009), "IT capabilities and firm performance: A contingency analysis of the role of industry and IT capability type", Information \& Management, Vol. 46, No. 3, pp. 181-9. http://dx.doi.org/10.1016/j.im.2008.10.002.

Danese, P., Molinaro, M. and Romano, P. (2018), "Managing evolutionary paths in Sales and Operations Planning: key dimensions and sequences of implementation", International Journal of Production Research, Taylor \& Francis, Vol. 56, No. 5, pp. 2036-53. http://dx.doi.org/10.1080/00207543.2017.1355119.

Doering, T. and Suresh, N.C. (2016), "Forecasting and performance: conceptualizing forecasting management competence as a higher-order construct", The Journal of Supply Chain Management, Vol. 52, No. 4, pp. 77-91. http://dx.doi.org/10.1111/jscm.12111.

Dutta, D. and Bose, I. (2015), "Managing a big data project: the case of Ramco Cements Limited", International Journal of Production Economics, Elsevier, Vol. 165, pp. 293-306. http://dx.doi.org/10.1016/J.IJPE.2014.12.032. 
Feng, Y., D'Amours, S. and Beauregard, R. (2008), "The value of sales and operations planning in oriented strand board industry with make-to-order manufacturing system: Cross functional integration under deterministic demand and spot market recourse", International Journal of Production Economics, Vol. 115, No. 1, pp. 189-209. http://dx.doi.org/10.1016/j.ijpe.2008.06.002.

Feng, Y., D'Amours, S. and Beauregard, R. (2010), "Simulation and performance evaluation of partially and fully integrated sales and operations planning", International Journal of Production Research, Vol. 48, No. 19, pp. 5859-83. http://dx.doi.org/10.1080/00207540903232789.

Feng, Y., Martel, A., D’Amours, S. et al. (2013), "Coordinated contract decisions in a make-to-order manufacturing supply chain: A stochastic programming approach", Production and Operations Management, Vol. 22, No. 3, pp. 642-60. http://dx.doi.org/10.1111/j.1937-5956.2012.01385.x.

Fildes, R., Goodwin, P. and Önkal, D. (2019), "Use and misuse of information in supply chain forecasting of promotion effects", International Journal of Forecasting, Vol. 35, No. 1, pp. 144-56. http://dx.doi.org/10.1016/j.ijforecast.2017.12.006.

Garcia-Villarreal, E., Bhamra, R. and Schoenheit, M. (2018), "A framework for technology selection to support sales and operations planning in german medical technology organisations", in EurOMA 2018, Budapest, Hungary, p. 1-9.

Genin, P., Thomas, A. and Lamouri, S. (2007), "How to manage robust tactical planning with an APS (Advanced Planning Systems)", Journal of Intelligent Manufacturing, Vol. 18, No. 2, pp. 209-21. http://dx.doi.org/10.1007/s10845-007-0015-y.

Goh, S.H. and Eldridge, S. (2019), "Sales and Operations Planning: The effect of coordination mechanisms on supply chain performance", International Journal of Production Economics, Vol. 214, pp. 80-94. http://dx.doi.org/10.1016/j.ijpe.2019.03.027.

Grimson, J.A. and Pyke, D.F. (2007), "Sales and operations planning: An exploratory study and framework", International Journal of Logistics Management, Vol. 18, No. 3, pp. 322-46. http://dx.doi.org/10.1108/09574090710835093.

Hahn, G.J. and Kuhn, H. (2012a), "Value-based performance and risk management in supply chains: A robust optimization approach", International Journal of Production Economics, Elsevier, Vol. 139, No. 1, pp. 135-44. http://dx.doi.org/10.1016/j.ijpe.2011.04.002.

Hahn, G.J. and Kuhn, H. (2012b), "Simultaneous investment, operations, and financial planning in supply chains: A value-based optimization approach", International Journal of Production Economics, Elsevier, Vol. 140, No. 2, pp. 559-69. http://dx.doi.org/10.1016/j.ijpe.2012.02.018.

Hopkins, M.S. and Brokaw, L. (2011), "Matchmaking with math: How analytics beats intuition to win customers", MIT Sloan Management Review, Vol. 52, No. 2, pp. 35-41.

Hulthén, H., Näslund, D. and Norrman, A. (2016), "Framework for measuring performance of the sales and operations planning process", International Journal of Physical Distribution \& Logistics Management, Vol. 46, No. 9, pp. 809-35. http://dx.doi.org/10.1108/IJPDLM-05-2016-0139.

Ivert, L.K. and Jonsson, P. (2010), "The potential benefits of advanced planning and scheduling systems in sales and operations planning", Industrial Management \& Data Systems, Vol. 110, No. 5, pp. 659-81. http://dx.doi.org/10.1108/02635571011044713.

Ivert, L.K., Dubovsk-Popovska, I., Fredriksson, A. et al. (2015), "Contingency between S\&OP design and planning environment", International Journal of Physical Distribution \& Logistics Management, Vol. 45, No. 8, pp. 747-73. http://dx.doi.org/10.1108/IJPDLM-04-2014-0088.

Ivert, L.K. and Jonsson, P. (2014), "When should advanced planning and scheduling systems be used in sales and operations planning", International Journal of Operations \& Production Management, Vol. 34, No. 10, pp. 1338-62. http://dx.doi.org/10.1108/IJOPM-03-2011-0088.

Jeble, S., Dubey, R., Childe, S.J. et al. (2018), "Impact of big data and predictive analytics capability on supply chain sustainability", The International Journal of Logistics Management, Emerald Publishing Limited, Vol. 29, No. 2, pp. 513-38. http://dx.doi.org/10.1108/IJLM-05-2017-0134.

Jonsson, P. and Holmström, J. (2016), "Future of supply chain planning: closing the gaps between practice and promise", International Journal of Physical Distribution \& Logistics Management, Vol. 46, No. 1, pp. 62-81. http://dx.doi.org/10.1108/IJPDLM-05-2015-0137.

Kaipia, R., Holmström, J., Småros, J. et al. (2017), "Information sharing for sales and operations planning: Contextualized solutions and mechanisms", Journal of Operations Management, Vol. 52, No. 1, pp. 1529. http://dx.doi.org/10.1016/j.jom.2017.04.001. 
Kamble, S.S. and Gunasekaran, A. (2020), "Big data-driven supply chain performance measurement system: a review and framework for implementation", International Journal of Production Research, Taylor \& Francis, Vol. 58, No. 1, pp. 65-81. http://dx.doi.org/10.1080/00207543.2019.1630770.

Kim, M., Jeong, J. and Bae, S. (2019), “Demand forecasting based on machine learning for mass customization in smart manufacturing", ACM International Conference Proceeding Series, pp. 6-11. https://doi.org/10.1145/3335656.3335658.

Klein, J., Mello, R., Cordes, A.K., Hellingrath, B. and Martins, R.A. (2018), “Big Data Analytics for Supply Chain Management: a review of empirical studies", in EurOMA 2018, Budapest, Hungary, pp. 1-9.

Krippendorff, K. (1970), "Estimating the Reliability, Systematic Error and Random Error of Interval Data", Educational and Psychological Measurement, Vol. 30, No. 1, pp. 61-70. http://dx.doi.org/10.1177/001316447003000105.

Krippendorff, K. (2004), "Reliability in Content Analysis", Human Communication Research, Vol. 30, No. 3, pp. 411-33. http://dx.doi.org/10.1111/j.1468-2958.2004.tb00738.x.

Kristensen, J. and Jonsson, P. (2018), "Context-based sales and operations planning (S\&OP) research", International Journal of Physical Distribution \& Logistics Management, Vol. 48, No. 1, pp. 19-46. http://dx.doi.org/10.1108/JJPDLM-11-2017-0352.

Lapide, L. (2005), "Sales and operations planning Part III: A diagnostic model", Journal of Business Forecasting, Vol. 24, No. 1, pp. 13-6.

Lim, L.L., Alpan, G. and Penz, B. (2013), “Coordinating Sales and Operations Management in Automobile Industry under Long Procurement Lead Times", IFAC Proceedings Volumes, Vol. 46, No. 9, pp. 64-69. https://doi.org/10.3182/20130619-3-RU-3018.00281.

Lim, L.L., Alpan, G. and Penz, B. (2014), "Reconciling sales and operations management with distant suppliers in the automotive industry: A simulation approach", International Journal of Production Economics, Elsevier, Vol. 151, pp. 20-36. http://dx.doi.org/10.1016/j.ijpe.2014.01.011.

Lim, L.L., Alpan, G. and Penz, B. (2015), “A simulation-optimization approach for managing the sales and operations planning in the automotive industry", in Proceedings - CIE 45: 2015 International Conference on Computers and Industrial Engineering, pp. 1-23.

Lim, L.L., Alpan, G. and Penz, B. (2017), "A simulation-optimization approach for sales and operations planning in build-to-order industries with distant sourcing: Focus on the automotive industry", Computers \& Industrial Engineering, Vol. 112, pp. 469-82. http://dx.doi.org/10.1016/j.cie.2016.12.002.

Mathrani, S. (2018), “Using Enterprise Systems to Enhance Sales and Services Agility in Manufacturing Firms", in Proceedings - 2018 5th Asia-Pacific World Congress on Computer Science and Engineering, APWC on CSE 2018, IEEE, pp. 57-64. https://doi.org/10.1109/APWConCSE.2018.00018.

Mishra, D., Gunasekaran, A., Papadopoulos, T. et al. (2016), "Big Data and Supply Chain Management: a review and bibliometric analysis", Annals of Operations Research, Vol. 270, No. 1-2, pp. 313-36. http://dx.doi.org/10.1007/s10479-016-2236-y.

Moher, D., Liberati, A., Tetzlaff, J. et al. (2009), "Preferred reporting items for systematic reviews and meta-analyses: The PRISMA Statement", PLoS Medicine, Vol. 6, No. 7, pp. 1-6. http://dx.doi.org/10.1371/journal.pmed.1000097. PMid:19621072.

Mongeon, P. and Paul-Hus, A. (2016), "The journal coverage of Web of Science and Scopus: a comparative analysis", Scientometrics, Vol. 106, No. 1, pp. 213-28. http://dx.doi.org/10.1007/s11192-015-1765-5.

Nemati, Y. and Alavidoost, M.H. (2019), "'AA fuzzy bi-objective MILP approach to integrate sales, production, distribution and procurement planning in a FMCG supply chain", Soft Computing", Springer Berlin Heidelberg, Vol. 23, No. 13, pp. 4871-90. http://dx.doi.org/10.1007/s00500-018-3146-5.

Nemati, Y., Madhoshi, M. and Ghadikolaei, A.S. (2017), "The effect of Sales and Operations Planning (S\&OP) on supply chain's total performance: A case study in an Iranian dairy company", Computers \& Chemical Engineering, Elsevier Ltd, Vol. 104, pp. 323-38. http://dx.doi.org/10.1016/j.compchemeng.2017.05.002.

Nguyen, T., Zhou, L., Spiegler, V. et al. (2018), "Big data analytics in supply chain management: A state-ofthe-art literature review", Computers and Operations Research, Elsevier Ltd, Vol. 98, pp. 254-64. http://dx.doi.org/10.1016/j.cor.2017.07.004.

Noroozi, S. and Wikner, J. (2016), "A modularized framework for sales and operations planning with focus on process industries", Production \& Manufacturing Research, Taylor \& Francis, Vol. 4, No. 1, pp. 65-89. http://dx.doi.org/10.1080/21693277.2016.1200502. 
Olhager, J. and Selldin, E. (2007a), "Strategic Choice of Manufacturing Planning and Control Approaches: Empirical Analysis of Drivers and Performance", Advances in Production Management Systems, Vol. 246, pp. 35-42. http://dx.doi.org/10.1007/978-0-387-74157-4_5.

Olhager, J. and Selldin, E. (2007b), "Manufacturing planning and control approaches: market alignment and performance", International Journal of Production Research, Vol. 45, No. 6, pp. 1469-84. http://dx.doi.org/10.1080/00207540600635250.

Omar, H., Hoang, V.H. and Liu, D.R. (2016), "A Hybrid Neural Network Model for Sales Forecasting Based on ARIMA and Search Popularity of Article Titles", Computational Intelligence and Neuroscience, Vol. 2016, pp. 1-9. http://dx.doi.org/10.1155/2016/9656453. PMid:27313605.

Pedroso, C.B., da Silva, A.L. and Tate, W.L. (2016), "Sales and Operations Planning (S\&OP): Insights from a multi-case study of Brazilian Organizations", International Journal of Production Economics, Elsevier, Vol. 182, pp. 213-29. http://dx.doi.org/10.1016/j.ijpe.2016.08.035.

Plank, R.E. and Hooker, R. (2014), "Sales and operations planning: Using the internet and internet-based tools to further supply chain integration", Journal of Research in Interactive Marketing, Vol. 8, No. 1, pp. 18-36. http://dx.doi.org/10.1108/JRIM-08-2013-0059.

Rappold, J.A. and Yoho, K.D. (2014), "Setting safety stocks for stable rotation cycle schedules", International Journal of Production Economics, Elsevier, Vol. 156, pp. 146-58. http://dx.doi.org/10.1016/j.ijpe.2014.05.020.

Ross, A. (2003), "Creating agile supply chains", Manufacturing Engineer, Vol. 82, No. 6, pp. 18-21.

Sanders, N. (2014), Big Data Driven Supply Chain Management: A framework for implementing analytics and turning information into intelligence, Pearson Education, Upper Saddle River, New Jersey.

Schoenherr, T. and Speier-Pero, C. (2015), "Data science, predictive analytics, and big data in supply chain management: current state and future potential", Journal of Business Logistics, Vol. 36, No. 1, pp. 120-32. http://dx.doi.org/10.1111/jbl.12082.

Seeling, M.X., Scavards, L.F. and Thomé, A.M.T. (2019), "A sales and operations planning application in the Brazilian subsidiary of a multinational chemical company", Brazilian Journal of Operations \& Production Management, Vol. 16, No. 8. http://dx.doi.org/10.14488/bjopm.2019.v16.n3.

Shaikh, S. (2018), "Sales and operations management in contemporary organizations: Operations and Service Management", IGI Global, Pennsylvania, pp. 974-95.

Singh, A., Jain, D., Mehta, I., Mitra, J. \& Agrawal, S. (2017), "Application of Big data in Supply Chain Management", Materials today: Proceedings, Elvsevier, Vol. 4, No. 2, pp. 1106-15. http://dx.doi.org/10.1016/J.MATPR.2017.01.126.

Sodhi, M.S. and Tang, C.S. (2011), "Determining supply requirement in the sales-and-operations-planning (S\&OP) process under demand uncertainty: A stochastic programming formulation and a spreadsheet implementation", The Journal of the Operational Research Society, Vol. 62, No. 3, pp. 52636. http://dx.doi.org/10.1057/jors.2010.93.

Song, H., Wang, L. and Wang, X. (2008), "The empirical study of IT application on performance in China pharmaceutical distribution industry", in 2008 IEEE International Conference on Service Operations and Logistics, and Informatics, IEEE, Beijing, China, Vol. 1, pp. 1102-07. https://doi.org/10.1109/SOLI.2008.4686564.

Souza, G.C. (2014), "Supply chain analytics", Business Horizons, Vol. 57, No. 5, pp. 595-605.

Suurmond, C. (2016), "Hard problems and soft information", in BMSD 2016 - Proceedings of the 6th International Symposium on Business Modeling and Software Design, pp. 32-38. https://doi.org/10.5220/0006221900320038.

Taşkin, Z.C., Ałrali, S., Ünal, A.T. et al. (2015), "Mathematical programming-based sales and operations planning at Vestel Electronics", Interfaces, Vol. 45, No. 4, pp. 325-40. http://dx.doi.org/10.1287/inte.2015.0793.

Thomas, A., Genin, P. and Lamouri, S. (2008), "Mathematical programming approaches for stable tactical and operational planning in supply chain and APS context", Journal of Decision Systems, Vol. 17, No. 3, pp. 425-55. http://dx.doi.org/10.3166/jds.17.425-455.

Thomas, A. and Lamouri, S. (2000), "The new problem with Sales, Inventories and Operations planning in a Supply Chain environment", Prodceedings of SPIE, Vol. 4192, pp. 321-9.

Thomé, A.M.T., Scavarda, L.F., Fernandez, N.S. et al. (2012), "Sales and operations planning: A research synthesis", International Journal of Production Economics, Vol. 138, No. 1, pp. 1-13. http://dx.doi.org/10.1016/j.jpe.2011.11.027. 
Thomé, A.M.T., Scavarda, L.F. and Scavarda, A.J. (2016), "Conducting systematic literature review in operations management", Production Planning and Control, Vol. 27, No. 5, pp. 408-20. http://dx.doi.org/10.1080/09537287.2015.1129464.

Trkman, P., McCormack, K., De Oliveira, M.P.V. et al. (2010), "The impact of business analytics on supply chain performance", Decision Support Systems, Vol. 49, No. 3, pp. 318-27. http://dx.doi.org/10.1016/j.dss.2010.03.007.

Tuomikangas, N. and Kaipia, R. (2014), "A coordination framework for Sales and Operations Planning (S\&OP): Synthesis from the literature", International Journal of Production Economics, Vol. 154, pp. $243-62$. http://dx.doi.org/10.1016/j.jpe.2014.04.026.

Vereecke, A., Vanderheyden, K., Baecke, P. et al. (2018), "Mind the gap - Assessing maturity of demand planning, a cornerstone of S\&OP", International Journal of Operations \& Production Management, Vol. 38, No. 8, pp. 161839. http://dx.doi.org/10.1108/IJOPM-11-2016-0698.

Wagner, S.M., Ullrich, K.K.R. and Transchel, S. (2014), "The game plan for aligning the organization", Business Horizons, Elsevier, Vol. 57, No. 2, pp. 189-201. http://dx.doi.org/10.1016/j.bushor.2013.11.002.

Wallace, T.F. and Stahl, R.A. (2008), "The demand planning process in executive S\&OP", The Journal of Business Forecasting, Vol. 27, No. 3, pp. 19-23.

Wang, J.Z., Hsieh, S.T. and Hsu, P.Y. (2012), "Advanced sales and operations planning framework in a company supply chain", International Journal of Computer Integrated Manufacturing, Vol. 25, No. 3, pp. 248-62. http://dx.doi.org/10.1080/0951192X.2011.629683.

Wang, J.Z. and Hsu, P.Y. (2010), "Advanced sales and operations planning based on integration of physical and financial flows", IEEM2010 - IEEE International Conference on Industrial Engineering and Engineering Management, IEEE, pp. 70-4. https://doi.org/10.1109/IEEM.2010.5674428.

Wery, J., Gaudreault, J., Thomas, A. et al. (2018), "Simulation-optimisation based framework for Sales and Operations Planning taking into account new products opportunities in a co-production context", Computers in Industry, Vol. 94, pp. 41-51. http://dx.doi.org/10.1016/j.compind.2017.10.002.

Wixom, B.H., Yen, B. and Relich, M. (2013), "Maximizing value from business analytics", MIS Quarterly Executive, Vol. 12, No. 2, pp. 111-23.

Wochner, S., Grunow, M., Staeblein, T. et al. (2016), "Planning for ramp-ups and new product introductions in the automotive industry: Extending sales and operations planning", International Journal of Production Economics, Elsevier, Vol. 182, pp. 372-83. http://dx.doi.org/10.1016/j.jpe.2016.07.008.

Wood, L.C., Reiners, T. and Srivastava, H.S. (2017), "Think exogenous to excel: alternative supply chain data to improve transparency and decisions", International Journal of Logistics Research and Applications, Taylor \& Francis, Vol. 20, No. 5, pp. 426-43. http://dx.doi.org/10.1080/13675567.2016.1267126.

Yu, W., Chavez, R., Jacobs, M.A. et al. (2018), "Data-driven supply chain capabilities and performance: A resourcebased view", Transportation Research Part E: Logistics and Transportation Review, Pergamon, Vol. 114, pp. 371 85. http://dx.doi.org/10.1016/J.TRE.2017.04.002.

Author contributions: F. N. P. Nicolas conceived the major research design, carried out the evaluation of the review, and took the lead in writing the manuscript. A. M. T. Thomé and F. N. P. Nicolas performed and evaluated the screening process. A. M. T. Thomé and B. Hellingrath contributed to the conceptualization and structuring of the research. All authors provided critical feedback and helped shape the research and analysis. 